\title{
ANALISIS PENELAAHAN PUISI RAKYAT DENGAN STRATEGI
} PQ4R

\author{
Lina Yuliawati ${ }^{1}$, Sutrimah ${ }^{2}$, Cahyo Hasanudin ${ }^{3 *}$ \\ Progam Studi Pendidikan Bahasa dan Sastra Indonesia, Fakultas Pendidikan Bahasa dan Seni, \\ IKIP PGRI Bojonegoro \\ e-mail : ${ }^{1}$ Linayulia040998@gmail.com, ${ }^{2}$ sutrimahyusuf@yahoo.com, ${ }^{* 3}$ cahyo.hasanudin@ \\ ikippgribojonegoro.ac.id
}

\begin{abstract}
ABSTRAK
Puisi rakyat merupakan karya satra yang tertentu bentuknya dan penyusunannya sesuai ekpresi penyair. Tujuan dari penelitian ini adalah untuk mengukur bagaimana kemampuan kelas VII dalam menelaah puisi rakyat (pantun, syair, dan gurindam). Penelitian ini merupakan penelitian deskriptif kualitatif. Pada penelitian ini menggunakan strategi PQ4R (Preview, Question, Read, Reflect, Recite, Review). Sumber data diambil dari jurnal nasional dan buku belajar siswa. Hasil penelitian ini menunjukkan bahwa: 1) bentuk telaah struktur dan kebahasaan pantun yang ditulis oleh siswa kelas VII SMP Negeri 3 Baureno dengan strategi PQ4R di katagorikan baik, 2) bentuk telaah struktur dan kebahasaan syair yang ditulis oleh siswa kelas VII SMP Negeri 3 Baureno dengan strategi PQ4R di katagorikan baik, dan 3) bentuk telaah struktur dan kebahasaan gurindam yang ditulis oleh siswa kelas VII SMP Negeri 3 Baureno dengan strategi PQ4R di katagorikan baik.
\end{abstract}

Kata Kunci: Puisi rakyat, Strategi PQ4R.

\section{Absract}

Folk poetry is literature work that has a certain form and composition according to the poet's expression. The purpose of this study is to measure how the ability of 7th grade students at studying folk poetry (pantun, poem, and gurindam). This study is a qualitative descriptive study. This study using the PQ4R strategy (Preview, Question, Read, Reflect, Recite, Review). Data sources were taken from national journals and student's learning books. The results of this study indicate that: 1) the form of structure and linguistic study of pantun written by 7th grade students of SMP Negeri 3 Baureno using PQ4R strategy categorized as good, 2) the form of structure and linguistic study of poem written by 7 th grade students of SMP Negeri 3 Baureno using PQ4R strategy is categorized as good, and 3) the form of structure and linguistic study of gurindam written by the 7th grade students of SMP Negeri 3 Baureno using PQ4R strategy categorized as good.

Keywords: folk poetry, PQ4R Strategy

\section{PENDAHULUAN}

Puisi rakyat diajarkan pada kurikulum 2013 SMP kelas VII semester 2, dengan KD 3.14 yang berbunyi menelaah struktur dan kebahasaan puisi rakyat (pantun, sya'ir, dan bentuk puisi rakyat setempat) yang dibaca dan didengar. Pada KD ini siswa diajarkan bagaimana menelaah struktur dan kebahasaan puisi rakyat, siswa akan diberikan 1-2 lembar kertas yang berisi puisi rakyat (pantun, sya'ir, dan gurindam). Siswa akan menelaah struktur dan kebahasaan yang ada pada puisi rakyat tersebut. Melalui pembelajaran inilah siswa akan belajar bagaimana menelaah struktur kebahasaan puisi rakyat yang baik dan benar.

Puisi rakyat adalah warisan budaya bangsa yang harus dipelihara [1]. Puisi rakyat adalah salah satu genre folklor lisan [2]. Puisi rakyat adalah yaitu salah satu dari sastra yang berbentuk lisan yang patut dibina dan dikembangkan agar tidak hilang oleh perkembangan zaman [3].

Pembelajaran puisi rakyat saat ini masih ditemukan kekurangan, baik dari siswa, guru, maupun materi yang masih dirasa itu masih sulit. Kemampuan menelaah puisi rakyat merupakan kemampuan yang sulit dipelajari oleh siswa [4]. Penyebabnya bisa jadi dari pembelajaran saintifik yang diterapkan sebelumnya masih kurang efektif [5]. Sehingga siswa kurang mampu dalam menelaah struktur dan kebahasaan puisi rakyat (pantun, syair, dan gurindam). 
Berdasarkan hasil wawancara dengan guru mata pelajaran Bahasa Indonesia kelas VII menelaah puisi rakyat masih ditemukan kekurangan. Oleh karena itu, perlu adanya strategi pembelajaran yang inovatif dalam menelaah puisi rakyat. Salah satu strategi pembelajaran yang dapat diterapkan yaitu strategi pembelajaran PQ4R (preview, question, read, reflect, recite, dan review). Strategi PQ4R cocok jika diterapkan dalam pembelajaran membaca karena di setiap langkah-langkahnya mengharuskan peserta didik untuk menghubungkan informasi dengan pengetahuan yang dimilikinya.

Strategi PQ4R merupakan strategi belajar yang bertujuan untuk memudahkan siswa dalam mengingat dan memahami materi yang dibaca [7]. Strategi PQ4R merupakan salah satu strategi yang diterapkan dalam pembelajaran untuk membantu peserta didik dalam mengingat apa yang sudah dibaca, dan membantu dalam kegiatan belajar mengajar yang dilakukan dengan membaca buku [8]. Metode PQ4R merupakan salah satu metode dalam strategi elaborasi [9].

Kelebihan strategi PQ4R yaitu dapat meningkatkan kreativitas peserta didik dalam belajar [10]. Kelebihan strategi PQ4R yaitu: 1) Cocok diterapkan dalam pengajaran pengetahuan yang bersifat deklaratif, 2) Bisa membantu siswa yang daya ingatannya rendah untuk menghafal konsep pelajaran, 3) Mudah diterapkan di semua jenis jenjang pendidikan, 4) Mampu membantu siswa dalam meningkatkan keterampilan bertanya dan mengomunikasikan pengetahuan yang dimilikinya, 5) Mampu menjangkau materi pelajaran dalam cakupan luas [11]. Strategi PQ4R diharapkan mampu membantu mengembangkan imajinasi siswa dalam menelaah puisi rakyat dengan baik sesuai indikator yang ditetapkan.

Penelitian yang dilakukan oleh Sukiman, Pratiwi, \& Widiati mengenai pengembangan modul puisi rakyat Sumbawa dengan menggunakan modul pengembangan desain 4-D bisa dibilang efektif dan dapat diterapkan dalam pembelajaran sastra di SMP [12]. Sedangkan penelitian yang dilakukan oleh Aini tentang penerapan strategi PQ4R dapat meningkatkan kemampuan membaca intensif siswa yang mengalami kesulitan dalam mengembangkan ide [13].

Pembelajaran yang menggunakan strategi PQ4R diharapkan dapat meningkatkan penelaahan puisi rakyat pada siswa kelas VII SMPN 3 Baureno. Selain itu, guru di SMPN 3 baureno belum pernah menerapkan strategi PQ4R dalam pembelajaran penelaahan puisi rakyat. Berdasarkan permasalahan tersebut peneliti tertarik untuk melakukan penelitian mengenai "Analisis Penelaahan Puisi Rakyat dengan Strategi PQ4R".

\section{METODOLOGI PENELITIAN}

Jenis penelitian ini adalah penelitian deskriptif kulitatif. penelitian kualitatif yaitu penelitian yang menitikberatkan pada pemahaman tentang masalah-masalah kehidupan sosial berdasarkan relitas, holistis, kompleks, dan rinci [14]. Data yang diperolah pada penelitian ini yaitu bagaimana bentuk telaah puisi rakyat (pantun, syair, dan gurindam) siswa kelas VII A SMP Negeri 3 Baureno yang di ajar menggunakan strategi PQ4R. Subjek penelitian ini adalah kelas VII A yang berjumlah 26 siswa, kemudian diambil 3 siswa yang dijadikan subjek penelitian untuk diwawancarai dengan alasan kemampuan menelaah puisi rakyat (pantun, syair, gurindam) bagus sesuai indikator.

Penelitian ini menggunakan sumber data primer yaitu data yang langsung diperoleh dari sumber data pertama di lokasi penelitian atau objek penelitian [15]. Sumber data pada penelitian ini yaitu siswa kelas VII A SMP Negeri 3 Baureno. Peneliti membuat catatan hasil wawancara dengan guru dan siswa, pelaksanaan pembelajaran yang telah dibuat guru dan peneliti, hasil tes sebagai tolak ukur kemampuan siswa dalam memahami telaah struktur dan kebahasaan puisi rakyat, hasil wawancara sebagai klarifikasi jawaban siswa terkait pemahaman telaah struktur dan kebahasaan pusi rakyat.

Prosedur pengumpulan data bertujuan untuk mendapatkan data. Prosedur pengumpulan data pada penelitian ini dilakukan cara sebagai berikut.

Observasi 
Penelitian ini melakukan observasi secara langsung, dengan melihat dan mengamati kejadian yang terjadi secara langsung peneliti akan mendapat data yang akurat.

Metode Tes

Tes yaitu teknik pengumpulan data yang dilakukan dengan memberikan soal atau tugas kepada subjek yang akan diteliti [16]. Langkah yang ditempuh peneliti dalam pengambilan data dengan menggunakan tes yaitu dengan menyiapkan bahan tes pada aplikasi google drive, kemudian siswa menjawab pertanyaan yang telah disediakan peneliti di googel drive, selanjutnya peneliti menilai serta mengolah data dari hasil kegiatan pembelajaran.

Teknik Wawancara

Teknik wawancara digunakan untuk memperoleh data dari guru dan siswa tentang telaah struktur dan kebahasaan puisi rakyat dengan strategi PQ4R di kelas. Melalui teknik wawancara responden diberi kesempatan untuk menjelaskan pendapatnya serta menceritakan pengalaman dan pengamatan yang sudah dilalui [17].

Teknik Analisis Data

Teknik analisis data yaitu cara mengolah data yang sudah diperoleh di lapangan [18]. Penelitian ini merupakan penelitian deskriptif kualitatif sehingga menggunakan analisis data nonstatistik dalam menganalis data.

Teknik Validasi Data (triangulasi)

Keabsahan penelitian ini menggunakan triangulasi data. Triangulasi adalah teknik pemeriksaan validitas data yang memanfaatkan sesuatu yang lain dari luar data untuk kepentingan pengecekan atau sebagai pembanding dari data tersebut [19].

Pada penelitian ini menggunakan triangulasi sumber dan metode. Langkah-langkah yang dilakukan pada triangulasi sumber yaitu melakukan perbandingan antara hasil pekerjaan siswa dalam menelaah puisi rakyat dan hasil wawancara. Langkah-langkah yang dilakukan pada triangulasi metode yaitu peneliti melakukan tes menelaah puisi rakyat pada siswa dan melakukan klarifikasi dengan hasil wawancara yang telah dilakukan. apabila terdapat kesamaan maka data tersebut dapat dinyatakan valid.

\section{HASIL DAN PEMBAHASAN}

\section{Hasil Penelitian}

Hasil penelitian ini mencakup 1) bentuk telaah struktur dan kebahasaan pantun, 2) bentuk telaah struktur dan kebahasaan syair, dan 3) bentuk telaah struktur dan kebahasaan gurindam. Hal ini dapat dijelaskan sebagai berikut.

\section{Bentuk Telaah Struktur dan Kebahasaan Pantun}

Berdasarkan pada pada paparan data telaah pantun yang ditulis oleh siswa, peneliti memberikan soal menelaah struktur dan kebahasaan pantun untuk mengetahui sejauh mana kemampuan siswa dalam menelaah struktur dan kebahasaan pantun. Berikut akan dijelaskan mengenai bentuk telaah struktur dan kebahasaan pantun yang ditulis oleh siswa kelas VII SMP Negeri 3 Baureno.

Pantun di atas mempunyai 2 struktur yaitu; sampiran dan isi. Baris 1 dan 2

merupakan sampiran, sedangkan baris 3 dan 4 merupakan isi.

Baris pantun kesatu menggunakan kiasan (makna konotatif), baris pantun

kedua menggunakan kalimat larangan (janganlah), baris pantun ketiga

menggunakan kalimat perintah (tuntutlah), dan baris pantun keeempat

merupakan jawaban dari baris ketiga.

Pantun di atas bersajak a-b-a-b. Mempunyai 42 suku kata, yang dibagi dalam

10 suku kata pada baris pertama, 10 suku kata pada baris kedua, 11 suku

kata pada baris ketiga dan 11 suku kata pada baris keempat.

Pada pantun di atas mempunyai kata penghubung tujuan (agar)

Gambar 1. Telaah pada pantun 
Pada lembar tes menelaah pantun siswa mampu menjawab 4 poin pertanyaan dengan baik, antara lain: siswa mampu memahami struktur pantun (sampiran dan isi) dengan baik, siswa mampu memahami suku kata yang digunakan pada pantun dengan baik, siswa mampu memahami sajak yang digunakan pantun dengan baik, siswa mampu memahami kalimat yang digunakan pantun pada baris 1, 2, 3, dan 4 dengan baik. Hal ini dapat dilihat pada kutipan wawancara sebagai berikut.
$L Y$
: Apa kamu paham struktur pantun?
IAI $\quad$ : Iya bu paham, struktur pantun dibagi menjadi 2 yaitu sampiran pada baris 1 dan 2, sedangkan isi terdapat pada baris 3 dan 4.
LY : Bagus. Apa kamu paham suku kata, terutama suku kata yang digunakan
pantun?
IA : Iya bu, paham. Biasanya dalam pantun terdapat 8-12 suku kata di setiap
barisnya.
LY $\quad$ : Bagus. Kamu paham kalimat yang digunakan pantun tersebut?
IAI :Paham bu.
LY $\quad$ : Baik. Kamu juga paham sajak pada pantun tersebut?
IAI $\quad$ : Iya bu, saya paham.

\section{Bentuk Telaah Struktur dan Kebahasaan Syair}

Berdasarkan pada pada paparan data telaah syair yang ditulis oleh siswa, peneliti memberikan soal menelaah struktur dan kebahasaan pantun untuk mengetahui sejauh mana kemampuan siswa dalam menelaah struktur dan kebahasaan syair. Berikut akan dijelaskan mengenai bentuk telaah struktur dan kebahasaan pantun yang ditulis oleh siswa kelas VII SMP Negeri 3 Baureno.

$$
\begin{aligned}
& \text { Struktur penyajian baris syair di atas terdiri dari } 4 \text { baris. } \\
& \text { Pola rima syair di atas yaitu a-a-a-a. dari baris 1-4 syair } \\
& \text { merupakan isi dan saling berkaitan satu sama lain. } \\
& \text { Kalimat yang digunakan syair di atas menggunakan } \\
& \text { kalimat perintah baris ke 1-3, sedangkan pada baris ke } 4 \\
& \text { merupakan akibat yang ditimbulkan dari baris 1-3. }
\end{aligned}
$$

\section{Gambar 2. Telaah pada Syair}

Pada lembar tes menelaah syair siswa mampu menjawab 4 poin pertanyaan dengan baik, antara lain: siswa mampu memahami jumlah baris yang digunakan syair dengan baik, siswa mampu memahami pola rima yang digunakan syair dengan baik, siswa mampu memahami hubungan antar baris dengan baik, siswa mampu memahami kalimat yang digunakan syair dengan baik. Hal ini dapat dilihat pada kutipan wawancara sebagai berikut.

LY : Kamu paham dengan rima akhir pada syair tersebut?

SNA : Iya bu, saya paham

LY : Kaтu paham berapa jumlah baris pada syair tersebut?

SNA : Iya, saya paham bu

LY : Baik. Kamu paham dengan kalimat yang digunakan pada syair tersebut pada baris 1-

4 ?

SNA : Iya bu, saya paham

LY : Bagus. Pertanyaan terakhir, kamu paham sebab dan akibat pada syair tersebut?

SNA : Iya bu, saya paham. 


\section{Bentuk Telaah Struktur dan Kebahasaan Gurindam}

Berdasarkan pada pada paparan data telaah gurindam yang ditulis oleh siswa, peneliti memberikan soal menelaah struktur dan kebahasaan gurindam untuk mengetahui sejauh mana kemampuan siswa dalam menelaah struktur dan kebahasaan gurindam. Berikut akan dijelaskan mengenai bentuk telaah struktur dan kebahasaan gurindam yang ditulis oleh siswa kelas VII SMP Negeri 3 Baureno.

$$
\begin{aligned}
& \text { Gurindam di atas terdiri dari } 2 \text { baris dan saling } \\
& \text { mempunyai hubungan. Baris pertama merupakan } \\
& \text { sebab terjadinya baris kedua.. dan baris kedua } \\
& \text { merupakan akibat dari baris pertama. } \\
& \text { Kalimat yang digunakan pada gurindam diatas } \\
& \text { menggunakan pola hubungan sebab-akibat. }
\end{aligned}
$$

Gambar 3. Telaah pada Gurindam

Pada lembar tes menelaah syair siswa mampu menjawab 3 poin pertanyaan dengan baik, antara lain: siswa mampu memahami baris gurindam dengan baik, siswa mampu memahami baris gurindam yang berisi sebab dan yang berisi akibat dengan baik, siswa mampu memahami kalimat yang digunakan gurindam dengan baik. Hal ini dapat dilihat pada kutipan wawancara sebagai berikut.
LY : Terimakasih Dwi. Pertanyaan pertama, kamu paham baris yang digunakan pada gurindam tersebut?
MDA : Iya bu, saya paham.
LY : Baik. Pertanyaan kedua, kamu paham hubungan antara baris 1 dan baris 2 pada gurindam tersebut?
MDA : Iya bu, saya paham.
LY : Baik. Pertanyaan ketiga, apakah kamu paham kalimat yang digunakan pada guridam tersebut.
MDA : Iya bu, saya paham.

\section{Pembahasan}

Bentuk telaah struktur dan kebahasaan pantun yang ditulis oleh siswa kelas VII SMP Negeri 3 Baureno cenderung baik. Siswa mampu menelaah pantun sesuai indikator dengan benar. Hal ini diperkuat oleh Faizah bahwa syarat penulisan pantun adalah: 1) Satu bait mempunyai empat baris, 2) Baris pertama dan kedua termasuk sampiran, baris ketiga dan keempat termasuk isi, 3) Setiap baris mempunyai 8-12 suku kata, 4) Mempunyai rima akhir yang berpola a-b-a-b, yang bearti bunyi akhir dari baris pertama sama dengan bunyi akhir baris ketiga dan bunyi akhir baris kedua sama dengan bunyi akhir baris keempat [20]. Hasil penelitian menunjukkan bahwa siswa mampu menelaah pantun sesuai indikator dengan benar.

Bentuk telaah struktur dan kebahasaan syair yang ditulis oleh siswa kelas VII SMP Negeri 3 Baureno cenderung baik. Siswa mampu menelaah syair sesuai indikator dengan benar. Hal ini diperkuat oleh Kusmayadi, Fitria, \& Rahmawati bahwa ciri-ciri syair sebagai berikut: 1) Syair terdiri atas 4 baris dalam setiap bait, 2) Syair tidak memiliki sampiran, 3) Syair tidak selesai dalam 1 bait, 4) Makna syair ditentukan oleh bait-bait berikutnya, 5) Anonim, 6) Pola rimanya berbunyi a-a-a-a (rima sama), 7) Irama terjadi pada setiap pertengahan baris diantara 4-6 suku kata [21]. Hal ini menujukkan bahwa siswa mampu menelaah syair sesuai indikator dengan baik.

Bentuk telaah struktur dan kebahasaan gurindam yang ditulis oleh siswa kelas VII SMP Negeri 3 Baureno cenderung baik. Siswa mampu menelaah syair sesuai indikator dengan benar. Hal ini diperkuat oleh Handayani \& Wildan bahwa ciri-ciri gurindam sebagai berikut: 1) terdiri 
dari 2 baris, 2) baris pertama berisi sebab dan baris kedua berisi akibat, 3) isinya mengandung nasehat-nasehat dan bersifat mendidik [22].

Kemampuan siswa kelas VII SMP Negeri 3 Baureno dalam menelaah struktur dan kebahasaan puisi rakyat (pantun, syair, dan gurindam) menunjukkan bahwa strategi PQ4R sangat cocok diterapkan pada kompetesi dasar 3.14. Penerapan strategi PQ4R memberikan pembaharuan dalam pembelajaran yang dapat memudahkan siswa dalam mengingat dan memahami materi yang dibaca siswa.

\section{SIMPULAN}

Berdasarkan rumusan masalah maka dapat disimpulkan bahwa 1) bentuk telaah struktur dan kebahasaan pantun yang ditulis siswa dapat dikategorikan baik. Siswa mampu menjawab 4 poin pertanyaan dengan baik, 2) bentuk telaah struktur dan kebahasaan syair yang ditulis siswa dapat dikategorikan baik, siswa mampu menjawab 4 poin pertanyaan dengan baik, 3) bentuk telaah struktur dan kebahasaan gurindam yang ditulis siswa dapat dikategorikan baik. Siswa mampu menjawab 3 poin pertanyaan dengan baik.

\section{DAFTAR RUJUKAN}

[1] Fitriani, P. (2017). Peningkatan keterampilan menulis puisi rakyat dengan model quantum teaching. Jurnal DIKSATRASIA, 286-293. https://jurnal.unigal.ac.id/index.php/diksatrasia/article/view/631.

[2] Firmansyah, H. (2013). Puisi sawer turun tanah di kecamatan Rajadesa kabupaten Ciamis (struktur, proses penciptaan, konteks penuturan, fungsi, dan makna). Antologi bahasa dan sastra Indonesia, 1(3), 1-10. https://ejournal.upi.edu/index.php/BS_Antologi_Ind/article/view/513.

[3] Haryanti, E. (2016). Lawas samawa dalam prosesi perkawinan tradisional etnik samawa. Jurnal TAMBORA, 1(3), 1-10. http://journal.uts.ac.id

[4] Yanti, N., Gafar, A., \& Rofii, A., (2018). Pengaruh penggunaan media gambar terhadap kemampuan menulis puisi rakyat siswa kelas VII SMP Negeri 6 kota Jambi tahun ajaran 2017/2018. Jurnal ilmiah pendidikan bahasa dan sastra Indonesia, 2(2), 67-76. http://aksara.unbari.ac.id/index.php/aksara/article/view/74

[5] Purwati, P. D. (2019). Pengembangan model elektik berbasis nilai luhur Pancasila dalam pembelajaran menulis puisi rakyat kelas VII SMP. Jurnal pendidikan bahasa dan sastra Indonesia, 8(1), 18-28. https://journal.unnes.ac.id/sju/index.php/jpbsi/article/view/21537

[6] Hasanudin, C. \& Hidayati, A. (2016). Eksperimentasi strategi belajar PQ4R dengan media komik terhadap keterampilan membaca pemahaman cerita anak pada siswa kelas VII SMP. Jurnal keilmuan bahasa, sastra, dan pengajarannya, 2(2) 136-142. http://ejournal.umm.ac.id/index.php/kembara/article/view/3998

[7] Noviyanti, T., Suripto, \& Joharman. (2015). Penerapan pembelajaran strategi PQ4R dalam peningkatan pembelajaran IPS kelas V SD Negeri Karangasem 02. Kalam cendekia PGSD Kebumen, $\quad 3(3), \quad 1-8$. http://www.jurnal.fkip.uns.ac.id/index.php/pgsdkebumen/article/view/1941/1426

[8] Wangka, A. \& Usman, M. (2016) Penerapan strategi pembelajaran PQ4R (preview, question, read, reflect, recite, dan review). Jurnal pendidikan agama islam, 1(1), 68-76. https://journal.unismuh.ac.id/index.php/tarbawi/article/view/359

[9] Linayaningsih, F. (2011). untuk meningkatkan prestasi belajar. Majalah ilmiah INFORMATIKA, 2(2), 75-86. http://www.unaki.ac.id/ejournal/index.php/majalah-ilmiahinformatika/article/view/41

[10] Saffaan, E \& febrianda. (2017). Peningkatan aktivitas dan hasil belajar siswa melalui strategi pembelajatan PQ4R (preview, question, read, reflect, recite, dan review). FITRA, 3(2), 104115. http://jurnal.staitapaktuan.ac.id/index.php/fitra/article/view/54 
[11] Darise, I., W. (2015). Pengaruh penerapan strategi pembelajaran PQ4R terhadap prestasi belajar peserta didik pada mata pelajaran SKI (sejarah kebudayaan islam) di MTs Negeri unggulan Manado. Jurnal Pendidikan islam iqra', 9(1), 35-61. https://www.neliti.com/publications/273945/pengaruh-penerapan-strategi-pembelajaranpq4r-terhadap-prestasi-belajar-peserta

[12] Sukiman, Pratiwi, Y., Widiati, N. (2017). Pengembangan modul puisi rakyat Sumbawa sebagai bahan pembelajaran sastra di SMP. Jurnal Pendidikan, 2(4), 556-561. http://journal.um.ac.id/index.php/jptpp/article/view/8878/4280

[13] Aini, N., Nasikin, I., Bariroh, Z. (2018). Montase dan pembelajaran: montase sebagai pembangunan daya fikir dan kreativitas anak usia dini. Ponorogo: Uwais Inspirasi Indonesia.

[14] Anggito, A. \& Setiawan, J. (2018). Metodeologi penelitian kualitatif. Sukabumi: CV Jejak.

[15] Bungin, M. B. (2017). Metodologi penelitian kuantitatif: komunikasi, ekonomi, dan kebijakan public serta ilmu-ilmu sosial lainnya. Jakarta: KENCANA.

[16] Nasrudin, J. (2019). Metodologi penelitian Pendidikan: buku ajar praktis cara membuat penelitian. Bandung: PT Panca Terra Firma.

[17] Nurdiani, N. (2014). Teknik sampling snowball dalam penilitian lapangan. ComTech, 5(2), $1110-1118$.

[18] Maryati, K. \& Suryawati, J. (2001). Sosiologi untuk SMA dan MA kelas XII standar isi 2006. Jakarta: Erlangga

[19] Pritandhari, M. (2016). Penerapan komik strip sebagai media pembelajaran mata kuliah manajemen keuangan mahasiswa universitas muhamadiyah Metro. Jurnal Pendidikan $\begin{array}{lllll}\text { ekonomi } \quad \text { M.M } & \text { Metro, }\end{array}$ http://ojs.fkip.ummetro.ac.id/index.php/ekonomi/article/view/631

[20] Faizah, S. (2018). Pengaruh projectbased learning terhadap kreativitas menulis puisi rakyat (PANTUN). Jurnal mahasiswa teknoligi Pendidikan, 9(2), 1-7. https://jurnalmahasiswa.unesa.ac.id/index.php/jmtp/article/view/27537/25196

[21] Kusmayadi, I., Fitria, D. A., \& Rahmawati, E. (2008). Be smart bahasa Indonesia untuk kelas IX SMP/MTS. Bandung: Grafido Media Pratama

[22] Handayani, S. \& Wildan. (2008). Persiapan UN bahasa Indonesia untuk SMP/MTs. Bandung: Grafido Media Pratama. 